Mailing Address: Ali A. Kawi, M.D., State University of New York, Downstate Medical Center, 450 Clarkson Avenue, Brooklyn, New York 11203.

\section{SOCIETY OF PROFESSORS OF CHILD PSYCHIATRY}

The Society of Professors of Child Psychiatry met March 18-20, 1977, in Key Biscayne, Florida. The primary concerns related to the external forces that seem to be impinging and shaping the training programs in child psychiatry.

Presentations were made by Dr. Larry B. Silver, Dr. Richard Ward, and Dr. Frank Rafferty around issues of PSRO and peer-review systems, the Committee on Certification in Child Psychiatry, and the Joint Commission on Accreditation on Hospitals. There was also discussion from the floor concerning the recently passed manpower legislation, which most of the membership of the society felt would be the greatest force in directing education in child psychiatry that we have seen for a number of years.
In the discussion groups, subsequently, the questions centered around how active the membership could be in helping write the regulations for legislation already passed, and also, how much influence could the individuals be in their own schools for developing and demonstrating a need for training in child psychiatry and in general psychiatry, as well as in all of the primary care specialties.

It was decided that the next annual meeting would be held in the southwest area of the country with the professors of child psychiatry of the Ohio-Kentucky area to be in charge of the program.

As always, the program is defined by the heads of divisions of child and adolescent psychiatry within that region. The chairman of this nonorganization is Henry Work, M.D., and the steering committee consists of Dr. Work and Drs. Irving Philips, Jerry Weiner, Judith Forgotson, Marshall Schechter, and James Sussex.

Mailing Address: Henry H. Work, M.D., American Psychiatric Association, 1700 18th Street, NW, Washington, D.C. 20009. 